Synthesis Alerts is a monthly feature to help readers of Synthesis keep abreast of new reagents, catalysts, ligands, chiral auxiliaries, and protecting groups which have appeared in the recent literature. Emphasis is placed on new developments but established reagents, catalysts etc are also covered if they are used in novel and useful reactions. In each abstract, a specific example of a transformation is given in a concise format designed to aid visual retrieval of information.

Synthesis Alerts is a personal selection by:

Robert Chow, John Christopher, Emma Guthrie, Philip Kocienski, Alexander Kuhl, Catherine McCusker, Robert Narquizian, and Sukhjinder Uppal of Glasgow University.

Georg Thieme Verlag does not accept responsibility for the accuracy, content, or selection of the data.

Article Identifier:

1437-210X,E;2000,0,04,0603,0608,ftx,en;X00400SS.pdf
The journals regularly covered by the abstractors are:

Angewandte Chemie International Edition

Bulletin of the Chemical Society of Japan

Chemical Communications

Chemistry A European Journal

Chemistry Letters

Collection Czechoslovak Chemical Communications

European Journal of Organic Chemistry

Helvetica Chimica Acta

Heterocycles

Journal of the American Chemical Society

Journal of Organic Chemistry

Organic Letters

Organometallics

Perkin Transactions 1

Synlett

Synthesis

Tetrahedron

Tetrahedron Asymmetry and Tetrahedron Letters

Zinc Trifluoromethanesulfonate
$\begin{aligned} & \text { A mediates the addition of terminal alkynes to } \\
& \text { nitrones, aldehydes, ketones and } \mathrm{N} \text {-tosyl } \\
& \text { aldimines. }\end{aligned}$
\begin{tabular}{l|l} 
D. E. Frantz, R. Fässler, E. M. Carreira J. Am. \\
Chem. Soc. 1999, 121, 11245.
\end{tabular}


A, in combination with chiral ligands, catalyses the asymmetric 1,4-addition of phenylboronic acids to 1-alkenylphosphonates.

T. Hayashi, T. Senda, Y. Takaya, M. Ogasawara

A

Cyclopentadienyl(1,4-cyclooctadiene)ruthenium(I) Chloride / N-Hydroxysuccinimide

The title reagent pair catalyse the

cycloisomerisation-oxidation of homopropargyl alcohols.

B. M. Trost, Y. H. Rhee J. Am. Chem. Soo $1999,121,11680$

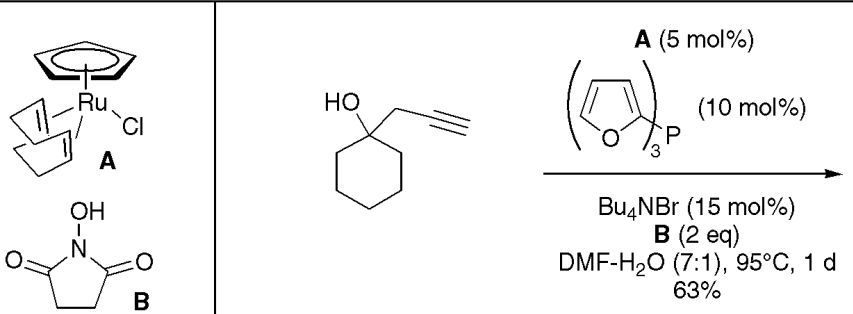

11 examples (yields $48-76 \%$ ).

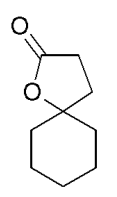

$63 \%$

\section{1,3-Dimesityl-4,5-dihydroimidazol-2-ylidene ruthenium benzylidene}

The title reagent is used in the preparation of trisubstituted alkenes via intermolecular olefin cross-metathesis.

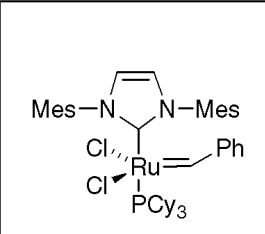

Mes $=\mathrm{C}_{6} \mathrm{H}_{2}-2,4,6-\mathrm{Me}_{3}$

A

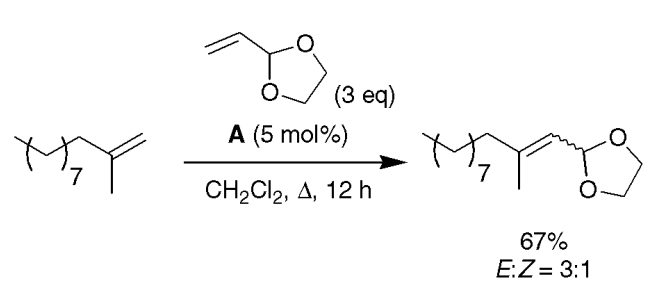

6 examples (yields 53-87\%, 2.3:1 $\leq E: Z \leq 4: 1$ ) are reported.

\section{Sodium Tetracarbonylcobaltate}

The title reagent catalyses the acylation of alcohols with acetic anhydride. The first example of a catalysed Staudinger reaction using a similar reagent is also reported.

H. Wack, W. J. Drury III, A. E. Taggi,

D. Ferraris, T. Lectka Org. Lett. 1999, 1, 1985.

\section{$\mathrm{NaCo}(\mathrm{CO})_{4}$}

A

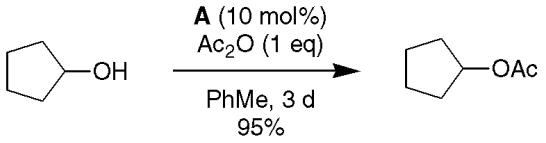

\section{The title reagent is shown to be an efficient Lewis acid catalyst for Friedel-Crafts acylation} and Diels-Alder reactions
J. Nishikido, F. Yamamoto, H. Nakajima, Y. Mikami, Y. Matsumoto, K. Mikami Synlett 1999, 1990

$\mid \begin{gathered}\mathrm{Sc}\left[\mathrm{C}\left(\mathrm{SO}_{2} \mathrm{C}_{4} \mathrm{~F}_{9}\right)_{3}\right]_{3} \\ \mathrm{~A}\end{gathered}$


A, generated from the title reagents catalyses an asymmetric nitro-Mannich-type reaction to give nitroamine products.

$$
\text { *1,1-binaphthyl }
$$

$$
\begin{aligned}
& \text { A }(20 \mathrm{~mol} \%) \\
& \mathrm{Ph}_{\mathrm{N}} \stackrel{\stackrel{\mathrm{O}}{\mathrm{II} P h_{2}}}{\wedge}
\end{aligned}
$$<smiles>O=[N+]([O-])C[C@@H](P[P+](=O)[O-])c1ccccc1</smiles>

$79 \%$, er $=96: 4$

K.-i. Yamada, S. J. Harwood, H. Gröger, M. Shibasaki Angew. Chem. Int. Ed. 1999, 38, 3504.

A

5 examples (yields $41-93 \%$, \%ee $=69-91 \%$ ).

The title compound catalyses the asymmetric addition of allylic trimethoxysilanes to aldehydes generating the corresponding homoallylic alcohols.
A. Yanagisawa, H. Kageyama, Y. Nakatsuka, K. Asakawa, Y. Matsumoto, H. Yamamoto Angew. Chem. Int. Ed. 1999, 38, 3701.

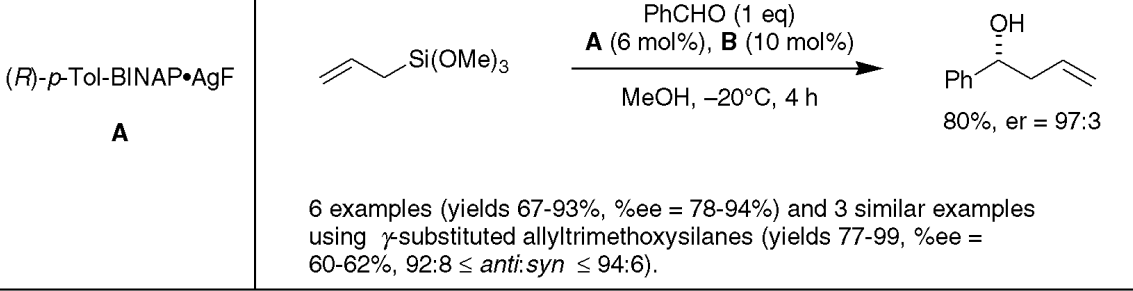

\section{Benzylimino[tris(dimethylamino)]phosphorane}

The title reagent catalyses the acylation of primary alcohols with enol esters in excellent yield and high selectivity.

P. Ilankumaran, J. G. Verkade J. Org. Chem. 1999, 64, 9063.

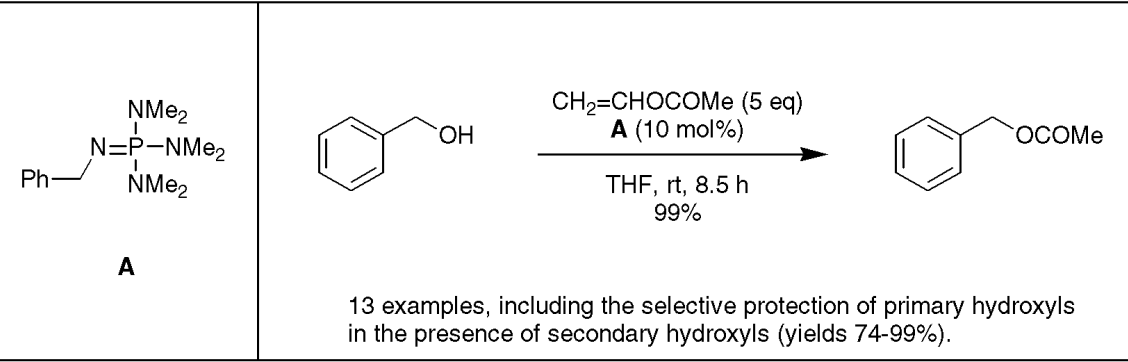

in the presence of secondary hydroxyls (yields $74-99 \%$ ).
The title compound catalyses the

enantioselective borane reduction of aromatic ketones.

G.-S. Yang, J.-B. Hu, G. Zhao, Y. Ding, M.-H. Tang Tetrahedron: Asymmetry 1999, 10, 4307.

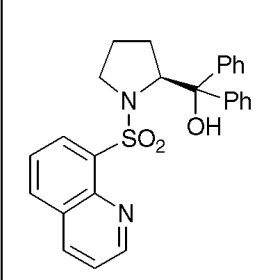

A

$$
\stackrel{\mathrm{Ph}}{\stackrel{\mathrm{O}}{\mathrm{Ar}(10 \mathrm{~mol} \%), \mathrm{BH}_{3} \cdot \mathrm{SMe}_{2}(1.1 \mathrm{eq})}} \underset{\mathrm{PhMe}, \Delta, 2 \mathrm{~h}}{\longrightarrow} \overbrace{\substack{96 \% \\ \mathrm{er}=96: 4}}^{\mathrm{OH}} \mathrm{Br}
$$

\begin{tabular}{l} 
Palladium Diacetate / Tri-tert-butylphosphine \\
\hline $\begin{array}{l}\text { The title reagent pair catalyses the reaction of } \\
\text { aryl halides with sodium } t \text {-butoxide to give aryl } \\
t \text {-butyl ethers. }\end{array}$ \\
$\begin{array}{l}\text { M. Watanabe, M. Nishiyama, Y. Koie } \\
\text { Tetrahedron Lett. 1999, 40,8837. }\end{array}$
\end{tabular}


A novel reduction of alcohols and alkyl ethers using the title reagent pair is reported.
V. Gevorgyan, J.-X. Liu, M. Rubin, S. Benson, Y. Yamamoto Tetrahedron Lett. 1999, 40, 8919.

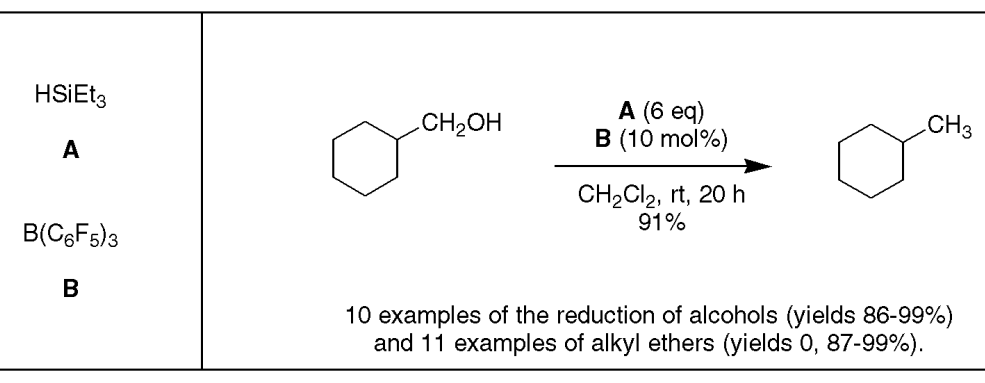

The title reagent is employed in the

enantioselective synthesis of $\alpha$-hydroxy acids.

J.-W. Chang, D.-P. Jang, B.-J. Uang, F.-L. Liao, S.-L. Wang Org. Lett. 1999, 1, 2061.

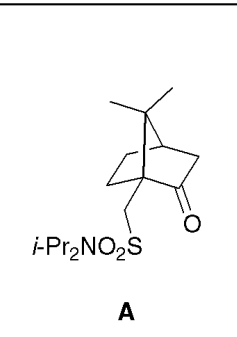
(a) $\mathrm{MeOH}$
$\left(\mathrm{CH}_{3} \mathrm{O}\right)_{3} \mathrm{CH}$
A
(b) $\mathrm{CH}_{3} \mathrm{CH}(\mathrm{OH}) \mathrm{CO}_{2} \mathrm{H}$
$\mathrm{BF}_{3} \cdot \mathrm{OEt}_{2}$
$\mathrm{Et}_{2} \mathrm{O},-45^{\circ} \mathrm{C}, 74 \%$

(c) LDA, HMPA
$\mathrm{CH}_{3} \mathrm{CH}_{2} \mathrm{I}$

THF, $-100^{\circ} \mathrm{C} \rightarrow-78^{\circ} \mathrm{C}$

(d) $\mathrm{NaOH}, \mathrm{MeOH}, \mathrm{HCl}$
Me, Et
$\mathrm{CO}_{2} \mathrm{H}$
$77 \%$
er $>99: 1$

5 examples of alkylations (yields $67-82 \%, \%$ de $>98 \%$ ) and 3 examples of the subsequent hydrolysis to acids (yields $94-98 \%$ ) are reported.

\section{Tricyclic Chiral Sultam Auxiliary}

Chiral Auxiliary

The use of the illustrated chiral auxiliary in asymmetric alkylations is described.

Tetrahedron 1999, 55, 13983

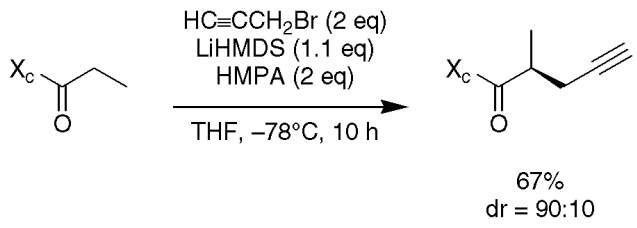

13 examples (yields $35-86 \%, \%$ de $=0,20-94 \%$ ).

\section{(-)-Cinchonidine}

The title reagent is used in the enantioselective indium-mediated allylation of aldehydes.

T.-P. Loh, J.-R. Zhou, Z. Yin Org. Lett. 1999 1,1855

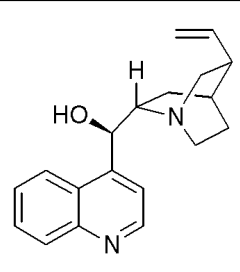

$\mathbf{A}$

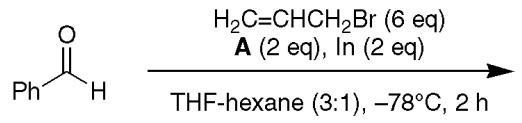

$\mathrm{OH}$

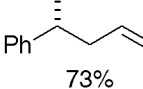

er $=88: 12$

\section{2-\{[(R)-2-Methylthiobutyl]-1-ferrocenyl\}diphenylphosphane}

A which has planar and central chirality, is utilised in Pd-catalysed allylic substitutions.

D. Enders, R. Peters, J. Runsink, J. W. Bats Org. Lett. 1999, 1, 1863.

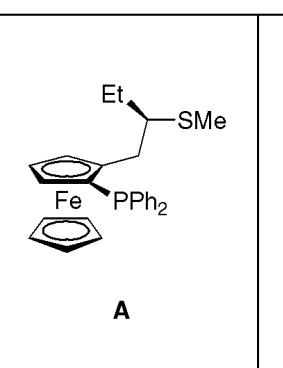

A $(2.2 \mathrm{~mol} \%)$

$$
\begin{aligned}
& \mathrm{Ph} / \mathrm{Ph} \quad\left[\mathrm{Pd}\left(\eta^{3}-\mathrm{C}_{3} \mathrm{H}_{5}\right) \mathrm{Cl}_{2}\right]_{2}(1 \mathrm{~mol} \%) \\
& \operatorname{KOAC}(1 \mathrm{~mol} \%), \mathrm{BSA}(3 \mathrm{eq}) \\
& \mathrm{CH}_{2}\left(\mathrm{CO}_{2} \mathrm{Me}\right)_{2} \text { (3 eq) } \\
& \mathrm{CH}_{2} \mathrm{Cl}_{2},-20^{\circ} \mathrm{C}, 1 \mathrm{~d} \\
& \overbrace{\mathrm{er}=100: 1}^{\mathrm{Ph}}
\end{aligned}
$$

2 examples (yields 50, 99\%, \%ee $=94,98 \%$ ) are reported. 
A promotes the Cu-catalysed enantioselective 1,4-addition of diethylzinc to acyclic enones.

X. Hu, H. Chen, X. Zhang Angew. Chem. Int Ed. $1999,38,3518$.

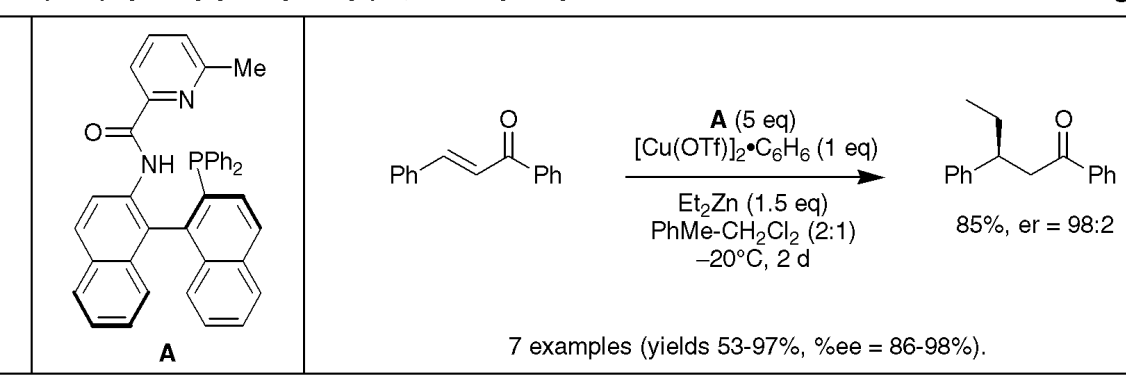

A or its l-enantiomorph promotes the enantioselective addition of disopropyl zinc to a pyrimidinyl carbaldehyde.
K. Soai, S. Osanai, K. Kadowaki, S.

Yonekubo, T. Shibata, I. Sato J. Am. Chem. Soc. 1999, 121, 11235.
7 examples (yields $53-97 \%$, \%ee $=86-98 \%$ ).

\section{Diisopropyloxy- $\eta^{2}$-propenetitanium(II)}

A, in combination with chiral acetals, serves as a chiral propionaldehyde homoenolate

equivalent which reacts with imines.

J. Am. Chem. Soc. 1999, 121, 11916.

$(i-\mathrm{PrO})_{2} \mathrm{Ti}$

\section{Allyltributyltin}

Reagent

A mediates the carbonylative radical coupling of alkyl iodides with phenylsulfonyl oxime ethers.

I. Ryu, H. Kuriyama, S. Minakata, M. Komatsu, J.-Y. Yoon, S. Kim J. Am. Chem. Soc. 1999, 121, 12190.

A

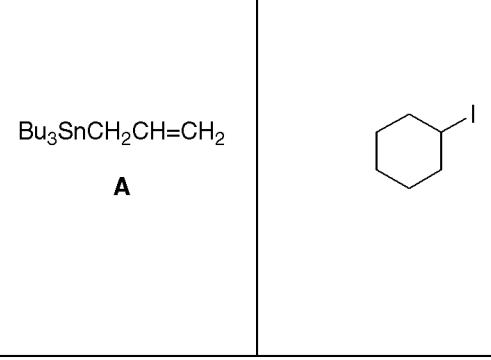

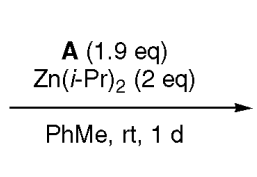<smiles>CC(C)[C@H](O)c1cnc(C#CC(C)(C)C)nc1</smiles>

17 examples (yields 90-97\%, \%ee = 80-97\%).

The title reagent promotes the selective $\mathrm{N}$-alkylation of primary amines.
R. N. Salvatore, A. S. Nagle, S. E. Schmidt, K. W. Jung Org. Lett. 1999, 1, 1893.

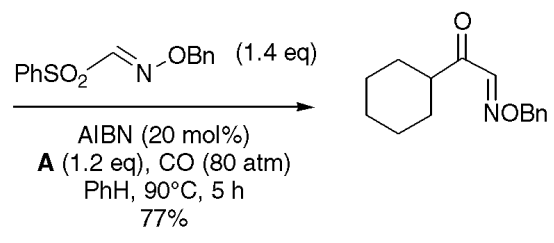

13 examples (yields $19-85 \%$ )

\begin{tabular}{l|l} 
& \\
R. N. Salvatore, A. S. Nagle, S. E. Schmidt, \\
K. W. Jung Org. Lett. 1999, 1, 1893.
\end{tabular}


The title reagent is used in the oxidative palladium-catalysed coupling of arenes with olefins.

C. Jia, W. Lu, T. Kitamura, Y. Fujiwara Org. Lett. 1999, 1, 2097.

A

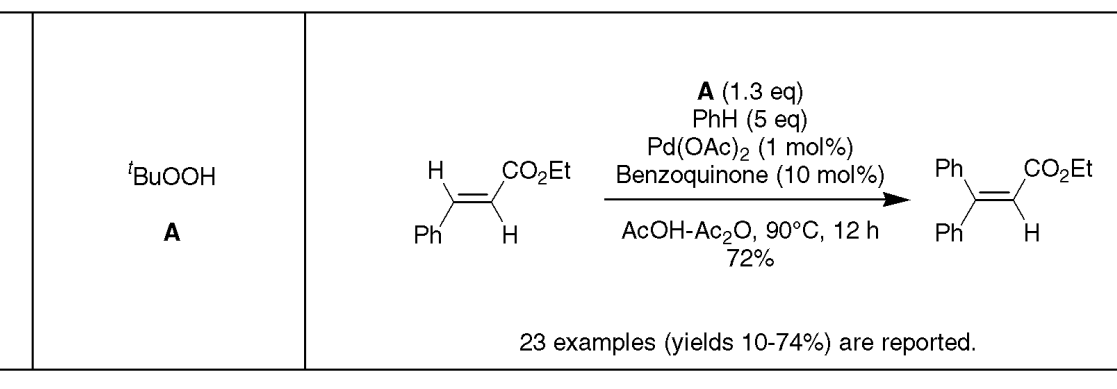

\section{Dimethyldioxirane}

Reagent

The title reagent is used to generate stable neutral solutions of hypoiodous acid, which is trapped in situ by addition to olefins to afford the corresponding iodohydrins.

G. Asensio, C. Andreu, C. Boix-Bernardini, R Mello, M. E. González-Nuñez Org. Lett. 1999, 1, 2125 . 